\title{
Child Nutrition and Health Campaign in 2012 in Zambia: Coverage Rates for Measles, Oral Polio Vaccine, Vitamin A, and De-worming
}

\author{
Olusegun Babaniyi ${ }^{1}$, Seter Siziya ${ }^{2, *}$, Victor Mukonka ${ }^{2}$, Penelope Kalesha ${ }^{3}$, Helen Mutambo ${ }^{1}$, Belem \\ Matapo $^{1}$ and Henry Musanje ${ }^{4}$ \\ ${ }^{1}$ World Health Organization Country Office, Lusaka, Zambia \\ ${ }^{2}$ Public Health Unit, Clinical Sciences Department, School of Medicine, Copperbelt University, Ndola, Zambia \\ ${ }^{3}$ Ministry of Community Development, Mother and Child Health, Lusaka, Zambia \\ ${ }^{4}$ Central Statistical Office, Lusaka, Zambia
}

\begin{abstract}
Introduction: Vaccines mitigate the severity of the diseases, prevent infections, and reduce the complications associated with infections. Following the 2012 measles campaign in Zambia, a cross sectional study was conducted to estimate coverage rates for measles, Oral Polio Vaccine (OPV), Vitamin A, and de-worming.

Materials and Methods: Using a cluster sampling method, 9 children were sampled for measles vaccination, Vitamin A and de-worming from each of the 40 clusters, and sampled 9 children in each of the 22 out of 40 clusters for OPV vaccination where it was distributed. Estimates and their $95 \%$ confidence intervals are reported.

Results: Data were available for analysis from 359 parent/care taker children pairs to determine measles coverage, 190 for OPV supplementation coverage, 270 for Vitamin A coverage, and 336 for de-worming coverage. Most of the children were aged 1 or 2 years $(57.8 \%$ in measles sample, $62.9 \%$ in OPV sample, $61.8 \%$ in Vitamin A sample, and $63.6 \%$ in deworming sample). A total of $345(96.1 \%)$ children were vaccinated against measles. A total of $157(83.1 \%)$ children received OPV, 257 (95.5\%) received Vitamin A, and 313 (93.4\%) were de-wormed. About 6 in 10 of the respondents reported that the health worker was the source of information and the key messages were encouraging children to go for vaccination and advantages for vaccination.
\end{abstract}

Conclusion: The 2012 measles campaign in Zambia was a great success but continued efforts are needed to adhere to the World Health Organization/United Nations Children's Fund (WHO/UNICEF) strategy to control measles.

Keywords: Coverage rates, De-worming, Measles, OPV, Post measles campaign, Vitamin A, Zambia.

\section{INTRODUCTION}

Measles continues to be a serious public health problem in both developing and developed countries despite the availability of a safe and effective vaccine. The incidence of measles in 2010 in the African region varied from 0 in the Central African Republic and Uganda to 526.3/100000 population in Malawi, with a regional total of 17.2/100000 population. Meanwhile, the incidence of measles in Zambia was 107.3/100000 populations [1].

Vitamin A deficiency is also a worldwide health problem, with a global prevalence of vitamin A deficiency in children aged $0-4$ years estimated at $21 \%$ in 2002 [2]. In 2003 , vitamin A deficiency was estimated to be at $53.3 \%$ in children aged below 5 years in Zambia [3].

*Address correspondence to this author at the Public Health Unit, Clinical Sciences Department, School of Medicine, Copperbelt University, P O Box 71191, Ndola, Zambia; Tel: +260-955-752646; Fax: +260-212-618511; E-mail: ssiziya@gmail.com
Infestation with soil transmitted helminths (worms) is a public health problem as it causes high morbidity among under five children; and deworming of children aged below five years has been adopted as one way of controlling helminths in Zambia [4]. In pre-school children in Kafue district of Zambia, Siwila et al. [5] found an overall prevalence of helminths infection of $17.9 \%$ : Ascaris lumbricoides $(12.0 \%)$, hookworm (8.3\%), Taenia spp. (0.9\%), Hymenolepis nana $(0.6 \%)$ and Schistosoma mansoni (0.3\%). Halwindi et al. [6] found that $16.4 \%$ of children aged $12-59$ months at baseline of the intervention had Ascaris lumbricoides, while hookworms were found in $7.0 \%$ of the children.

The reported annual incidence of poliomyelitis cases has declined by $70 \%$ from 5126 cases in 1980 to 1597 in 1995 in Africa [7]. By mid-2005 wild polio virus cases were reported from countries neighbouring Zambia: Angola, Botswana [8], Zaire [9] and Namibia [10,11]. Although, the last indigenous case of polio in Zambia was reported in 1995, 3 cases of Wild Polio Virus were virologically confirmed amongst Angolan refugees in Western Zambia in 2001 [12]. 
Vaccination at national level saves millions of lives annually [13]. Nationwide vaccination campaigns reduced measles mortality from one million deaths per year in the 1980 s to between 300,000 and 580,000 during the 1990s in the African region [14]. Apart from preventing diseases, vaccines also mitigate the severity of the diseases, prevent infections, and reduce the complications associated with infections [15]. Sustained reduction in measles mortality can be achieved if routine immunization is improved, all children are given a second dose of measles vaccine, measles case management is improved, and measles surveillance is carefully conducted [16]. However, problems of vaccine failure may lead to epidemics $[17,18]$.

Vitamin A deficiency is a recognized risk factor for severe measles [19]. The reduction in measles morbidity with vitamin A supplements is well documented [20,21]. In Nairobi, Kenya, Ogaro et al. [22] found that high dose vitamin A reduced the severity of complications of measles. Imdad et al. [23] reported that vitamin A supplements reduces incidence of measles morbidity by $50 \%$.

Low polio vaccine coverage of less than the $80 \%$ target in countries that reported cases of polio may partly explain the resurgence of wild polio virus transmission [8]. Coverage of the fourth dose of oral polio vaccine (OPV) called OPV3 of $70 \%-90 \%$ and an estimated vaccine efficacy with three or four doses of OPV of $80 \%-85 \%$ may result in a substantial accumulation of susceptible children annually [24] and lead to an epidemic. It is thus important that Zambia maintains at least $80 \%$ coverage for OPV to avoid the resurgence of wild polio virus transmission.

Zambia started providing immunization services in 1975 when the Expanded Programme on Immunization (EPI) was introduced, and in 1984 the programme was re-focussed to a Universal Child Immunization (UCI) in order to widen coverage. Over the years from when UCI was introduced, im- munization coverage improved. In 2001 and 2008, measles vaccine coverage in Zambia was $84 \%$ and $85 \%$, respectively. Meanwhile, the average annual measles incidence per 100,000 population reduced from 98.7 to 2.4 between 2001 2004 and 2005-2008 [14]. However in 2011, measles incidence rate per 100,000 population was 97.6 [25]. As a result of this epidemic, the government of the Republic of Zambia with the assistance of the World Health Organization (WHO) and the United Nations Children's Fund (UNICEF) conducted a national vaccination campaign in July 2012 covering measles, OPV, Vitamin A and de-worming. Following this campaign, a cluster survey was conducted with the aim of obtaining information on the delivery and impact of 2012 integrated Campaign. Specifically we determined the post campaign coverage for each of the activities and identified the reasons of non administration to beneficiaries and documented measles knowledge on the campaign and information sources.

\section{MATERIALS AND METHODS}

\section{Target Population}

The integrated campaign targeted $6,458,977$ children aged 6 months to 15 years to be vaccinated against measles; 2,494,884 aged 6 to 59 months to receive Vitamin A supplementation countrywide; 2,217,675 aged 12 to 59 months to be de-wormed and $1,257,558$ children aged 0 to 59 months to receive OPV in 30 polio high risk districts.

\section{Survey Design and Study Area}

A cross sectional study was conducted to estimate coverage rates for measles, OPV, Vitamin A, and de-worming. The survey was designed to produce estimates for the entire country. At the time of the survey, Zambia had 10 provinces with 74 districts (Fig. 1a).

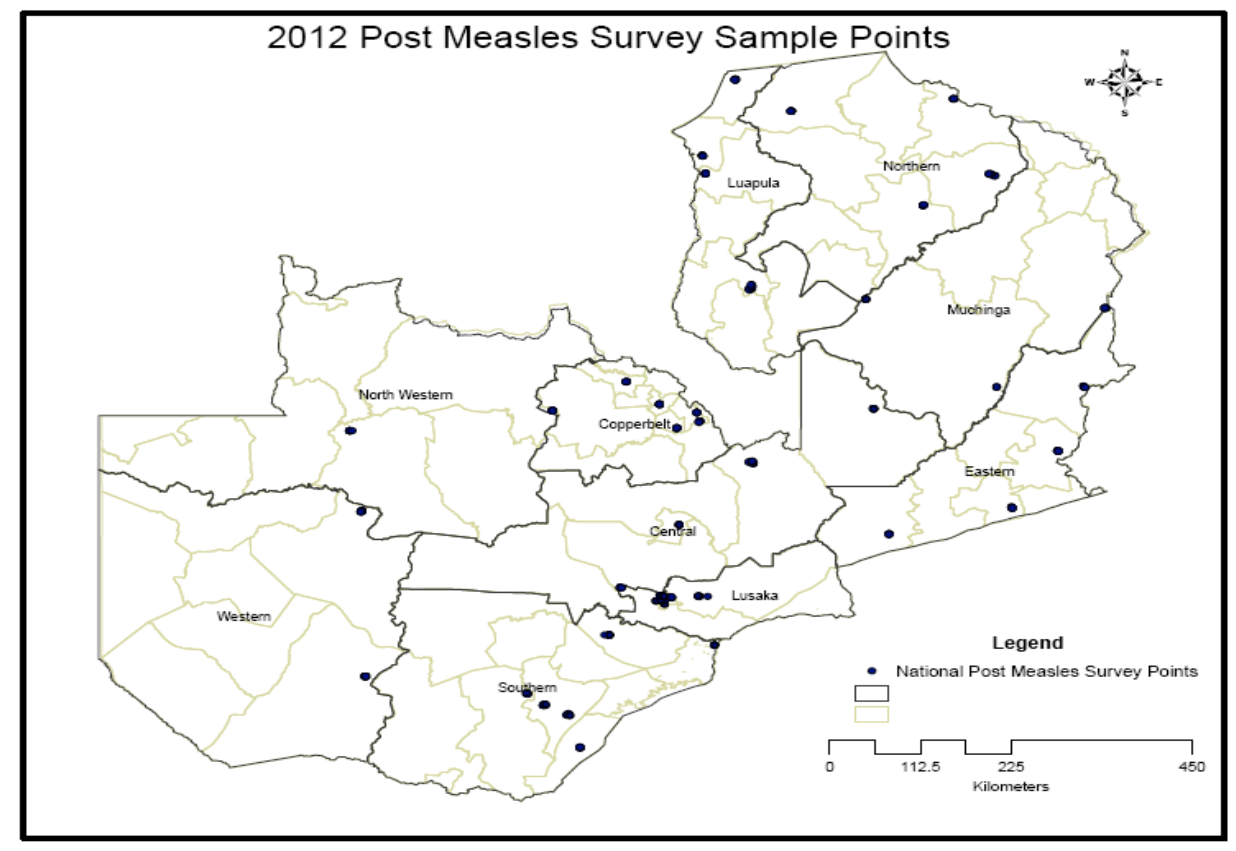

Fig. (1a). Post Measles Campaign Sample Point. 


\section{Sample Size and Sampling}

To determine the number of children to be surveyed, the following parameters were required: number of selected clusters, desired level of precision, and expected immunization coverage.

The number of survey clusters and children per cluster was determined in reference to established EPI coverage survey guidelines [26]. The EPI coverage survey manual provides guidance on the necessary number of children per cluster that must be sampled for desired precision of $+3 \%,+$ $5 \%$, and $+10 \%$, respectively. The expected immunization coverage levels in the Zambia EPI programme are different for routine and Supplementary Immunization Activities (SIA) strategies. For this survey, 40 clusters by 9 households, based on 2012 SIAs coverage, were adopted with a precision level of $\alpha=0.05$ and a design effect of 2 . The previous SIA coverage levels were obtained from the 2010 performance coverage by districts where the sampled SEAs were located.

$N=\frac{D E F F * Z_{1-\alpha / 2}^{2} * p(1-p)}{d^{2}}$

Where $\mathrm{p}$ is the expected coverage, Design Effect $(\mathrm{DEFF})=2$, and Precision $(\mathrm{d})=0.05$.

Using the following parameters: expected coverage of $88 \%$ from the 2010 post measles SIAs coverage survey for the under 5 years conducted countrywide $(\boldsymbol{p}=.88)$ and a desired width of the confidence interval of $\pm 5 \%(\boldsymbol{d}=5)$, and assuming a design effect of 2 , the minimum required sample size for children 324.5. Therefore, the minimum number of children to sample in each cluster was $324 / 40=8.1$. We considered sampling 9 children for measles vaccination from each cluster, giving a total sample size of 360 children.

When we considered an OPV expected coverage of $92 \%$ from the 2011 post OPV SIA survey conducted in 8 districts of Western and North-Western provinces. We opted to sample 9 children in each of the 22 out of 40 clusters in which OPV was administered during the campaign.

Zambia is administratively, divided into ten provinces. Each province is in turn subdivided into districts. Each district is further subdivided into constituencies and wards. For statistical purposes each ward is subdivided into Census Supervisory Areas (CSAs) and these are in turn subdivided into Standard Enumeration Areas (SEAs). The 2008-2010 census mapping exercise in preparation for the 2010 census of population and housing, demarcated the CSAs within wards, wards within constituencies and constituencies within districts. In total, at the time of constructing the 2010 census frame, Zambia had 74 districts, 150 constituencies, and 1,421 wards. Wards are further divided into Census Supervisory Areas (CSAs), which are in turn divided into Standard Enumeration Areas (SEAs). The SEAs are also stratified by urban and rural strata. The listing of SEAs has information on number of households and the population. The SEAs were the primary sampling units (PSUs) or the clusters.

The sample selection was done in two stages with the initial sampling of clusters (SEAs) as the PSUs and then selected 9 households. In each selected cluster, the first house- hold that was selected was located in the middle of the cluster. The direction to follow from the middle of the cluster was selected at random. The remaining children were selected in that direction. If the number of children (9) was not met, the team went back to the middle of the cluster and selected a direction at random and went in that direction until the required number of children was surveyed. One eligible child was selected per household and the youngest where there was more than one child. If twins were present in a selected household, both twins were then selected.

OPV coverage evaluation was conducted in 22 out of the 40 clusters selected for measles coverage evaluation because OPV vaccine was not administered to all districts in the country. Fig. (1a) shows the country-wide distribution of sample points.

\section{Data Collection}

Informed consent was obtained from the respondent before the interview could start. The respondent was first asked whether the child had an immunization card obtained from the recent campaign. If so, the interviewer transcribed the information from the card to the questionnaire. If not, the interviewer asked the respondent whether the child had received the interventions in the recently ended campaign. If the child received the intervention, the date when that was given was noted on the questionnaire, otherwise the intervention was reported given or not given. Questionnaires comprised of the following items: parent/caretaker demographic factors, child's age and sex, campaign card seen or not, evidence of indelible mark for immunization and whether measles dose, Vitamin A, OPV dose or Mebendazole tablet for de-worming were given during the campaign. The other items in the questionnaires were on reasons for failure to receive measles vaccination, vitamin A, OPV vaccination and Mebendazole. Another questionnaire elicited questions on sources of information about the campaign and what were their key messages, and knowledge on the administration of the measles vaccine, vitamin $\mathrm{A}$, OPV vaccine and Mebendazole.

\section{Data Management and Analysis}

Data were computerized using Microsoft Office Excel 2007. It was edited using range and consistency checks. A cleaned file was then exported to SPSS version 17 for data analysis. Analyses comprised running frequencies and computing 95\% confidence intervals upon using Complex samples program in SPSS.

\section{RESULTS}

Data were available for analysis from 359 parent/care taker children pairs to determine measles coverage, 190 for OPV supplementation coverage, 270 for Vitamin A coverage, and 336 for de-worming coverage.

\section{Sample Description (Parents/Care Takers)}

About half of the respondents were below the age of 30 years $52.3 \%$ in the measles sample, $58.4 \%$ in the OPV sample, $53.7 \%$ in the Vitamin A sample, and $53.5 \%$ in the deworming sample). About ninety percent of the respondents 
were females $(89.7 \%$ in the measles sample, $94.2 \%$ in the OPV sample, $91.1 \%$ in the Vitamin A sample and $91.4 \%$ in the de-worming sample), and 3 in 4 of the respondents belonged to the Protestant religion $(74.9 \%$ in the measles sample, $73.7 \%$ in the OPV sample, $75.9 \%$ in the Vitamin A sample, and $76.2 \%$ in the de-worming sample)). About half (51.0\% in the measles sample, $48.4 \%$ in the OPV sample, $53.0 \%$ in Vitamin A sample, and $51.2 \%$ in de-worming sample) and a third (34.5\% in measles sample, $39.5 \%$ in OPV sample, $34.1 \%$ in Vitamin A sample, and $35.4 \%$ in deworming sample) had obtained primary and secondary levels of education, respectively. The majority of the respondents were housewives $(57.1 \%$ in measles sample, $50.0 \%$ in OPV sample, $57.8 \%$ in Vitamin A sample, and 56.55 in deworming sample). These results are shown in Table 1.

About 6 in 10 of the children were aged 1 or 2 years (57.8\% in measles sample, $62.9 \%$ in OPV sample, $61.8 \%$ in Vitamin A sample, and 63.6\% in de-worming sample), and there were slightly more males than females in all the samples $(50.7 \%$ in measles sample, $54.7 \%$ in OPV sample, $52.4 \%$ in Vitamin A sample, and $51.2 \%$ in de-worming sam- ple) as shown in Table 2.

\section{Coverages for Measles, OPV, Vitamin A and de-worming}

A total of $345(96.1 \%)$ were vaccinated against measles. A total of 157 (83.1\%) received OPV, 257 (95.5\%) received Vitamin A, and 313 (93.4\%) were de-wormed. The results are shown in Table 3.

\section{Evidence of Participation in the Campaign, Vaccination Sites, and Reasons for Not Being Immunised or Receiv- ing Vitamin A or Mebendazole}

Immunization cards were seen in over half of the children (56.0\% in the measles sample, $57.7 \%$ in the OPV sample, $56.5 \%$ in the Vitamin A sample, and $58.5 \%$ in the deworming sample), respectively. Meanwhile, indelible mark was seen in less than ten percent of the children $(5.6 \%$ in measles sample, $6.9 \%$ in OPV sample, $7.1 \%$ in Vitamin A sample, and $4.5 \%$ in de-worming sample). About half of the children $(52.5 \%$ in measles sample, $49.7 \%$ in OPV sample, $57.0 \%$ in Vitamin A sample, and $52.9 \%$ in de-worming sample) received measles or OPV vaccines or Vitamin A or Me-

Table 1. Socio-economic Characteristics of the Parents/Care Takers

\begin{tabular}{|c|c|c|c|c|}
\hline Factor & Measles Total=359 n (\%) & OPV Total=190 n (\%) & Vitamin A Total $=270 \mathrm{n}(\%)$ & De-worming Total=336 n (\%) \\
\hline \multicolumn{5}{|l|}{ Age (years) } \\
\hline $25-29$ & $97(27.0)$ & $56(29.5)$ & $76(28.1)$ & $95(28.3)$ \\
\hline $30-34$ & $57(15.9)$ & $30(15.8)$ & $48(17.8)$ & $53(15.8)$ \\
\hline $40+$ & $69(19.2)$ & $29(15.3)$ & $45(16.7)$ & $60(17.9)$ \\
\hline \multicolumn{5}{|l|}{ Sex } \\
\hline Male & $37(10.3)$ & $11(5.8)$ & $24(8.9)$ & $29(8.6)$ \\
\hline Female & $322(89.7)$ & $179(94.2)$ & $246(91.1)$ & $307(91.4)$ \\
\hline \multicolumn{5}{|l|}{ Religion } \\
\hline Protestant & $269(74.9)$ & $140(73.7)$ & $205(75.9)$ & $256(76.2)$ \\
\hline Other & $24(6.7)$ & $7(3.7)$ & $20(7.4)$ & $21(6.3)$ \\
\hline \multicolumn{5}{|l|}{ Education } \\
\hline None & $34(9.5)$ & $15(7.9)$ & $22(8.1)$ & $29(8.6)$ \\
\hline Primary & $183(51.0)$ & $92(48.4)$ & $143(53.0)$ & $172(51.2)$ \\
\hline Secondary & $124(34.5)$ & $75(39.5)$ & $92(34.1)$ & $119(35.4)$ \\
\hline Tertiary & $18(5.0)$ & $8(4.2)$ & $13(4.8)$ & $16(4.8)$ \\
\hline
\end{tabular}


Table 2. Age and Sex Distributions of Children Aged 6 Months to 15 Years

\begin{tabular}{|l|c|c|c|c|}
\hline \multicolumn{1}{|c|}{ Factor } & Measles Total=359 n (\%) & OPV Total=190 n (\%) & Vitamin A Total=270 n (\%) & De-worming Total=336 n (\%) \\
\hline \hline Age (years) & & & & \\
\hline$<1$ & $14(3.9)$ & $6(3.2)$ & $84(31.1)$ & $107(31.8)$ \\
\hline 1 & $102(28.5)$ & $61(32.8)$ & $83(30.7)$ & $107(31.8)$ \\
\hline 2 & $105(29.3)$ & $56(30.1)$ & $57(21.1)$ & $77(22.9)$ \\
\hline 3 & $69(19.3)$ & $40(21.5)$ & $39(14.4)$ & $45(13.4)$ \\
\hline 4 & $44(12.3)$ & $23(12.4)$ & - & - \\
\hline $5+$ & $24(6.7)$ & - & & $141(52.4)$ \\
\hline Sex & & & $104(54.7)$ & $128(47.6)$ \\
\hline Male & $182(50.7)$ & $86(45.3)$ & $(51.2)$ \\
\hline Female & $178(49.3)$ & & & $164(48.8)$ \\
\hline
\end{tabular}

Table 3. Coverages for Measles, OPV, Vitamin A and De-worming

\begin{tabular}{|l|c|c|c|}
\hline \multicolumn{1}{|c|}{ Factor } & Total & n (\%) & [95\% Confidence Interval] \\
\hline \hline Measles & 359 & $345(96.1)$ & {$[92.2,98.1]$} \\
\hline OPV & 190 & $157(83.1)$ & {$[68.9,91.6]$} \\
\hline Vitamin A & 270 & $257(95.5)$ & {$[90.6,97.9]$} \\
\hline De-worming & 336 & $313(93.4)$ & {$[88.8,96.2]$} \\
\hline
\end{tabular}

bendazole from government health facilities. These results are shown in Table 4.

Districts with children who had cases of measles were observed in the eastern part of the country in Luapula, Central and Eastern provinces as shown in Fig. (1b).

\section{Sources of Information and key Messages About the Campaign, Knowledge on How Vaccines, Vitamin A and Mebendazole were Administered}

Most of the respondents reported that the health worker was the source of information about the campaign (62.6\% in measles sample, $60.8 \%$ in OPV sample, $63.7 \%$ in Vitamin A sample, and $64.0 \%$ in de-worming sample), while about thirty percent of the respondents indicated that the radio/television was the source of information about the campaign $(29.1 \%$ in measles sample, $28.0 \%$ in OPV sample, $30.0 \%$ in Vitamin A sample, and 30.7\% in de-worming sample). The most frequently reported key messages were encouraging children to go for vaccination $(64.7 \%$ in measles sample, $69.1 \%$ in OPV sample, 64.8\% in Vitamin A and $64.9 \%$ in de-worming sample) and advantages for vaccination $(65.5 \%$ in measles sample, $66.9 \%$ in OPV sample, $54.8 \%$ in Vitamin A sample, and $63.4 \%$ in de-worming sample). Most of the respondents knew how to administer measles vaccine, Vitamin A or Mebendazole (98.3\% in measles sample, $98.4 \%$ in Vitamin A sample, and $95.5 \%$ in deworming sample) but only $59.9 \%$ of the respondents knew how to administer OPV. These results are shown in Table 5.

\section{DISCUSSION}

With the measles coverage of $96.1 \%$ in the current survey, Zambia meets the needed coverage for fully protective herd immunity of between 94\% and 97\% [27]. However, with primary vaccination failure occurring at $4 \%-8 \%$ and secondary failure at about $4 \%$, high measles coverage may not be the determining factor to control the disease. The successful nationwide measles vaccination campaign has already resulted in a drastic reduction of reported measles cases in Zambia despite heightened surveillance due to the high measles vaccination coverage [25]. Some countries have adopted a two-dose policy: one dose in infancy and a booster, usually at school age in order to control measles [28], but Zambia is currently scheduled to introduce second dose measles in 2013.

While OPV coverage was on a low side at $83.1 \%$, Vitamin A and Mebendazole coverages were above 90\%. Since OPV was not administered to all districts, the observed low coverage may be a reflection of the mal-distribution of the vaccine. The high level of Vitamin A coverage indicated that the risk of developing respiratory disease, diarrhoea, measles and vision problems and dying may be reduce [23].

We found that about half of the children had the immunization card and less than ten percent of the children had the indelible mark. The post measles survey was conducted late such that the mark was not visible on most of the children's figures. It is important to emphasize the importance of keeping the immunization card as evidence of immunization. It is 


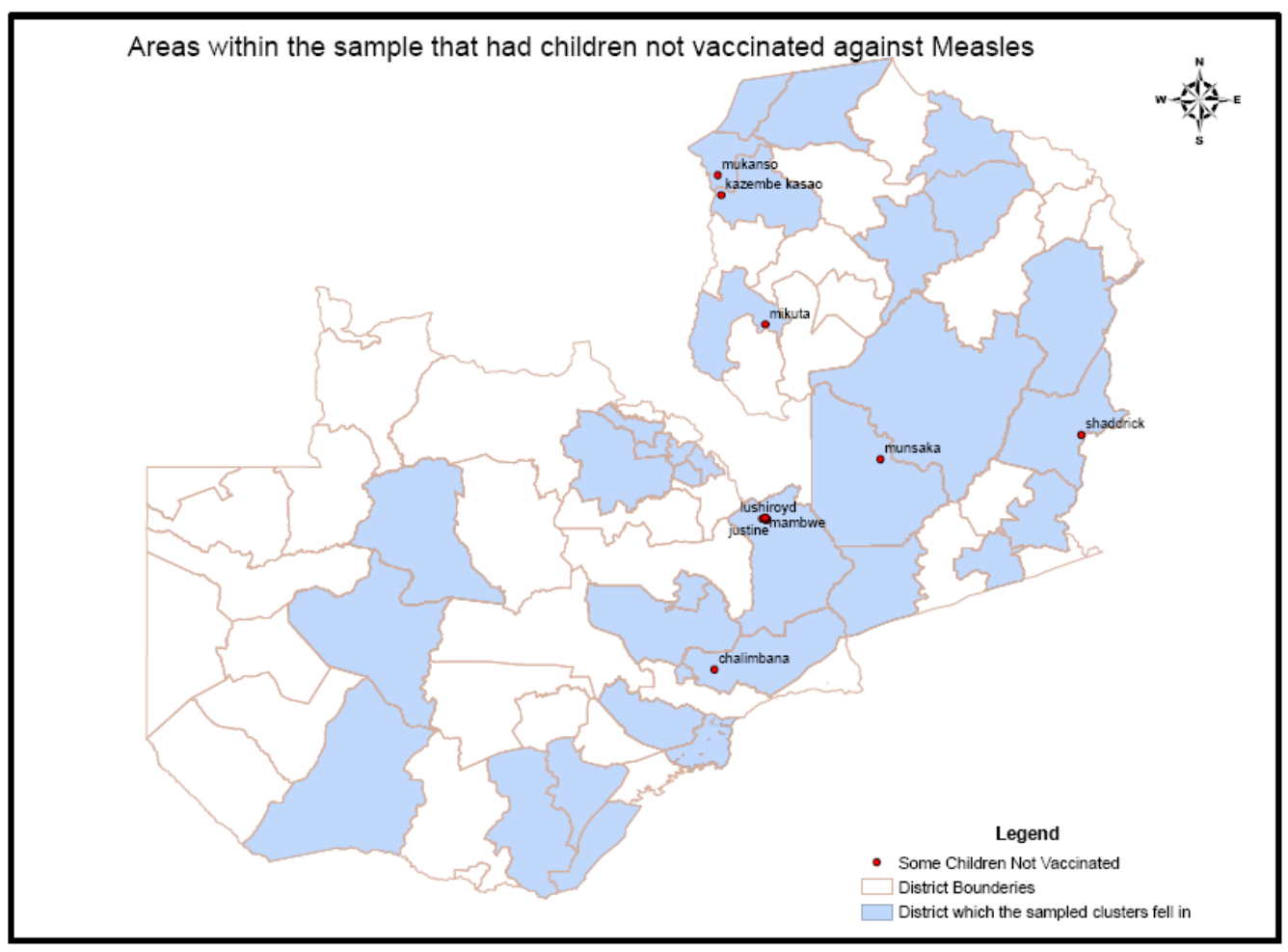

Fig. (1b). Areas within the sample that had some children not vaccinated against measles.

Table 4. Evidence of Participation in the Campaign, Vaccination Sites, and Reasons for Failure

\begin{tabular}{|c|c|c|c|c|}
\hline Factor & $\begin{array}{c}\text { Measles Total=359 } \\
\text { n (\%) }\end{array}$ & $\begin{array}{c}\text { OPV Total }=190 \\
\text { n (\%) }\end{array}$ & $\begin{array}{c}\text { Vitamin A Total=270 } \\
\text { n (\%) }\end{array}$ & $\begin{array}{c}\text { De-worming Total=336 } \\
\text { n (\%) }\end{array}$ \\
\hline \multicolumn{5}{|c|}{$\begin{array}{l}\text { Evidence of having participated in the } \\
\text { campaign }\end{array}$} \\
\hline \multicolumn{5}{|l|}{ Immunisation card* } \\
\hline Seen & $201(56.0)$ & $109(57.7)$ & $152(56.5)$ & $196(58.5)$ \\
\hline \multicolumn{5}{|l|}{ Indelible mark } \\
\hline Seen & $20(5.6)$ & $13(6.9)$ & $19(7.1)$ & $15(4.5)$ \\
\hline Not seen & $339(94.4)$ & $176(93.1)$ & $250(92.9)$ & $320(95.5)$ \\
\hline Private health facility & $4(1.2)$ & $2(1.3)$ & $3(1.2)$ & $3(1.0)$ \\
\hline Public place (mobile) & $19(5.5)$ & $13(8.3)$ & $10(3.9)$ & $17(5.4)$ \\
\hline Private school & $8(2.3)$ & $2(1.3)$ & $11(4.3)$ & $7(2.2)$ \\
\hline Government school & $36(10.4)$ & $14(8.9)$ & $20(7.8)$ & $28(8.9)$ \\
\hline
\end{tabular}

* number not adding up to totals due to missing data

equally important that the immunization card is equally distributed to all immunization centres.

While the majority of the vaccination site was the government health facility, it is pleasing to note that the school (both private and public) was also the site for vaccination in about ten percent of the children. In the just ended campaign, children in the age group 6 months to 15 years were eligible for measles vaccination whether vaccinated before or not.

The main source of information about the campaign was the health worker, followed by the radio/television. These 
Table 5. Sources of Information About the Campaign

\begin{tabular}{|c|c|c|c|c|}
\hline Factor & $\begin{array}{c}\text { Measles Total }=358 \\
\text { n (\%) }\end{array}$ & $\begin{array}{c}\text { OPV Total=186 } \\
\text { n (\%) }\end{array}$ & $\begin{array}{c}\text { Vitamin A Total=270 } \\
\text { n (\%) }\end{array}$ & $\begin{array}{c}\text { De-worming Total=336 } \\
\text { n (\%) }\end{array}$ \\
\hline \multicolumn{5}{|l|}{ Sources of information about the campaign } \\
\hline Radio/Television & $104(29.1)$ & $52(28.0)$ & $81(30.0)$ & $103(30.7)$ \\
\hline Newspaper & $2(0.6)$ & $0(0)$ & $1(0.4)$ & $0(0)$ \\
\hline Poster/Pamphlet & $12(3.4)$ & $1(0.5)$ & $10(3.7)$ & $9(2.7)$ \\
\hline Health worker & $224(62.6)$ & $113(60.8)$ & $172(63.7)$ & $215(64.0)$ \\
\hline Traditional leader & $30(8.4)$ & $9(4.8)$ & $19(7.0)$ & $30(8.9)$ \\
\hline School children & $20(5.6)$ & $6(3.2)$ & $18(6.7)$ & $18(5.4)$ \\
\hline Other & $104(29.1)$ & $50(26.9)$ & $63(23.3)$ & $83(24.7)$ \\
\hline Not informed by any source & $1(0.3)$ & $2(1.1)$ & $2(0.7)$ & $2(0.6)$ \\
\hline Key messages about the campaign & Total $=357$ & Total $=181$ & Total $=270$ & Total $=336$ \\
\hline Encouraging children to go for vaccination & $231(64.7)$ & $125(69.1)$ & $175(64.8)$ & $218(64.9)$ \\
\hline Places to go for vaccination & $147(41.2)$ & $73(40.3)$ & $77(28.5)$ & $133(39.6)$ \\
\hline Advantages for vaccination & $234(65.5)$ & $121(66.9)$ & $148(54.8)$ & $213(63.4)$ \\
\hline Other message & $2(0.6)$ & $1(0.6)$ & $1(0.4)$ & $3(0.9)$ \\
\hline
\end{tabular}

sources may not be the ideal sources in populations with limited access to health facilities and radio/television given the high poverty level in Zambia. School-going children and traditional leaders should be widely used to disseminate information on campaigns.

About ten percent of the parents/care takers took an hour or more to get to the vaccination sites. More vaccination sites should be created in order to easy access to the sites.

\section{CONCLUSION}

The 2012 measles campaign in Zambia was a great success but continued efforts are needed to adhere to the WHO/UNICEF strategy to control measles.

\section{CONFLICT OF INTERESTS}

The authors declare that they have no competing interests.

\section{ACKNOWLEDGEMENTS}

We are grateful to the participants for their cooperation in the study. The efforts made by the research assistants towards the successful completion of the survey are gratefully acknowledged. The World Health Organization Country Office, Lusaka, Zambia and the Ministry of Health [Zambia] funded the study.

\section{REFERENCES}

[1] CDC. Measles outbreaks and progress towards measles preelimination --- African region, 2009-2010. Morbidity and Mortality Weekly Report 2011, 60, 374-378.

[2] WHO. World Health Report. Reducing Risk, Promoting Healthy Life. Geneva: WHO, 2002, 54-55.
[3] MoH. Measles supplementation immunization 2007 (with vitamin A supplementation, Mebendazole administration and retreatment of bed nets). Immunization campaign technical report, 2007. Ministry of Health [Zambia]: Lusaka, 2007.

[4] MoH. Measles supplementation immunization 2007: with vitamin A supplementation, Mebendazole administration and retreatment of bed nets. Immunization campaign technical report. Ministry of Health [Zambia]: Lusaka, 2007.

[5] Siwila, J.; Phiri, I.G.; Enemark, H.L.; Nchito, M.; Olsen, A. Intestinal helminths and protozoa in children in pre-schools in Kafue district, Zambia. Trans. R. Soc. Trop. Med. Hyg., 2010, 104, 122-128.

[6] Halwindi, H.; Magnussen, P.; Siziya, S.; Handema, R.; Meyrowitsch, D.W.; Olsen, A. Impact of community-directed treatment on soil transmitted helminth infections in children aged 12 to 59 months in Mazabuka District, Zambia. Parasitology, 2011, 138, 1578-1585.

[7] WHO EPI. EPI information system: summary for the WHO African Region. Publication no. WHO/EPVCEIS/96.01. World Health Organization: Geneva, 1996.

[8] Arevshatian, L.; Clements, C.; Lwanga, S.; Misore, A.; Ndumbe, P.; Seward, J.; Taylor, P. An evaluation of infant immunization in Africa: is a transformation in progress? Bull. World Health Organ., 2007, 85, 449-457.

[9] Okwo-Bele, J.M.; Lobanov, A.; Biellik, R.J.; Birmingham, M.E.; Pierre, L.; Tomori, O.; Barakamfitiye, D. Overview of Poliomyelitis in the African region and current regional plan of action. J. Infect. Dis., 1997, 175(Suppl 1), SI0-S15.

[10] van Niekerk, A.B.; Vries, J.B.; Baard, J.; Schoub, B.D.; Chezzi, C.; Blackburn, N.K. Outbreak of paralytic poliomyelitis in Namibia. Lancet, 1994, 344, 661-664.

[11] Biellik, R.J.; Allies, T.; Woodfill, C.J.; Lobanov, A. Polio outbreaks in Namibia, 1993-1995: lessons learned. J. Infect. Dis., 1997, I75(Suppl 1), S30-S36.

[12] WHO. Zambia ready to vaccinate over one million children against Polio. 23 July 2002. Available: http://www.afro.who.int/en/zambia/pressmaterials/item/368-zambia-ready-to-vaccinate-over-onemillion-child-renagainst-polio.html [Accessed December 15, 2012].

[13] Jamison, D.T.; Feachem, R.G.; Mkgoba, M.W.; Bos, E.R.; Baingana, F.K.; Hofman, K.J.; Rogo, K.O. Ed. Disease and mortality in sub-Saharn Africa. $2^{\text {nd }}$ ed.; World Bank: Washington DC, 2006. 
[14] CDC. Progress towards measles control-African region, 20012008. September 25, 2009/58(37); 1036-1041. Available: http://www.cdc.-gov/mmwr/preview/mmwrhtml/mm5837a3.htm. (Accessed December 16, 2012).

[15] Andre, F.E.; Booy, R.; Bock, H.L.; Clemens, J.; Datta, S.K.; John, T.J.; Lee, B.W.; Lolekha, S.; Peltola, H.; Ruff, T.A.; Santosham, M.; Schmitt, H.J. Vaccinations greatly reduces disease, disability, death and inequity worldwide. Bull. World Health Organ., 2008, 86, 140-146.

[16] WHO; UNICEF. Joint statement: Global plan for reducing measles mortality reduction and regional elimination straetegic plan 20062010. Available: http://www.who.int/vaccines-documents/DocsPDF06/WHO_IVB_05_11.pdf [Accessed December 16, 2012].

[17] Edmonson, M.B.; Addiss, D.G.; McPherson, J.T.; Berg, J.L.; Circo, S.R.; Davis, J.P. Mild measles and secondary vaccine failure during a sustained outbreak in a highly vaccinated population. JAMA, 1990, 263, 2467-2471.

[18] Nkowane, B.M.; Bart, S.W.; Orenstein, W.A.; Baltier, M. Measles outbreak in a vaccinated school population: epidemiology, chains of transmission and role of vaccine failures. Am. J. Public Health, 1987, 77, 434-438.

[19] Frieden, T.R.; Sowell, A.L.; Henning, K.J.; Huff, D.L.; Gunn, R.A. Vitamin A levels and severity of measles. New York City. Am. J. Dis. Child., 1992, 146, 182-186.

[20] Fawzi, W.W.; Chalmers, T.C.; Herrera, M.G.; Mosteller, F. Vitamin A supplementation and child mortality. A meta-analysis. JAMA, 1993, 269, 898-903.
[21] Hussey, G.D.; Klein, M. A randomized, controlled trial of vitamin A in children with severe measles. N. Eng. J. Med., 1990, 323, 160164.

[22] Ogaro, F.O.; Orinda, V.A.; Onyango, F.E.; Black, R.E. Effect of vitamin $\mathrm{A}$ on diarrhoeal and respiratory complications of measles. Trop. Geogr. Med., 1993, 45, 283-286.

[23] Imdad, A.; Herzer, K.; Mayo-Wilson, E.; Yakoob, M.Y.; Bhutta, Z.A. Vitamin A supplementation for preventing morbidity and mortality in children from 6 months to 5 years of age. Cochrane Database Syst. Rev., 2010, 12, CD008524.

[24] Patriarca, P.A.; Wright, P.F.; John, T.J. Factors affecting the immunogenicity of oral poliovirus vaccine in developing countries: review. Rev. Infect. Dis., 1991, 13, 926-939.

[25] WHO. Reported measles cases and incidence rates by WHO member states 2011, 2012 as of 5 November 2012. Available: http://www.who.int/immunization_monitoring/diseases/ measlesreportedcasesbycountry.pdf [Accessed December 16, 2012].

[26] WHO. Immunization coverage cluster survey-Reference manual: Immunization, vaccines and biological. WHO/IVB/04.23, WHO June 2005, Geneva. Available: http://www.measlesrubellainitiative. org/mifiles/Tools/Guidelines/WHO/Immunization $\% 20$ Coverage $\% 2$ 0Cluster\%20Survey\%20-\%20Reference\%20Manual.pdf [Accessed April 12, 2013].

[27] Markowitz, L.F.; Orenstein, W.A. Measles vaccines. Pediatr. Clin. North Am., 1990, 37, 603-625.

[28] Tulchinsky, T.H.; Ginsberg, G.M.; Abed, Y.; Angeles, M.T.; Akukwe, C.; Bonn, J. Measles control in developing and developed countries: the case for a two-dose policy. Bull. World Health Organ., 1993, 71: 93-103.

(C) Babaniyi et al.; Licensee Bentham Open.

This is an open access article licensed under the terms of the Creative Commons Attribution Non-Commercial License (http://creativecommons.org/licenses/by-nc/3.0/) which permits unrestricted, non-commercial use, distribution and reproduction in any medium, provided the work is properly cited. 